\title{
Making Sense of Microdevelopment, Macrodevelopment, and Their Interrelation
}

\author{
Commentary on van der Steen, Steenbeek, den Hartigh, and van Geert
}

\author{
David C. Witherington \\ University of New Mexico, Albuquerque, NM, USA
}

\begin{abstract}
Keywords
Microdevelopment · Macrodevelopment · Dynamics · Circular causality ·

Constraint $\cdot$ Time scales
\end{abstract}

In empirically mapping real-time student-teacher dynamics onto interindividual variability in long-term student learning trajectories, van der Steen, Steenbeck, den Hartigh, and van Geert (this issue) add significantly to one of developmental science's most important, yet critically underexplored, areas of investigation: time scale interrelations in development (e.g., Guevara, Cox, van Dijk, \& van Geert, 2017; Kunnen, Lichtwarck-Aschoff, \& van Geert, 2012; Lewis, 2002; Lichtwarck-Aschoff, van Geert, Bosma, \& Kunnen, 2008; Montes, van Dijk, Puche, \& van Geert, 2017). Consistent with most research in this area, van der Steen et al. specifically focus on how the realtime activities and processes of microdevelopment give rise to large-scale patterns of stability and directional change characteristic of macrodevelopment. But these authors are also quick to acknowledge the "circular relationship" that constitutes micromacro time scale interrelations, writing that "(w)hile real-time processes produce patterns of change that shape our development on the long term, established patterns of development also influence real-time iterative processes". With this commentary, I more fully consider ways to conceptualize microdevelopment, macrodevelopment, and their circular relations.

It is fairly common for micro- and macrodevelopment to be distinguished primarily, if not exclusively, along the dimension of time itself (Granott \& Parziale, 2002; Lewis, 2002; Thelen \& Smith, 1994; van Gelder \& Port, 1995). Microdevelopment involves shorter time scale processes of emergent organization (unfolding over seconds, minutes, and days), whereas macrodevelopment involves longer time scale processes of emergent organization (unfolding over months and years). Definitions of this sort often vary with respect to what particular units of time are considered constitutive of short-term, as opposed to long-term, processes of change. Nonetheless, by virtue of foregrounding time,

\section{KARGER}

(c) 2019 S. Karger AG, Basel

E-Mail karger@karger.com www.karger.com/hde
David Witherington

Department of Psychology

MSC03-2220, University of New Mexico

Albuquerque, NM 87131-1161 (USA)

E-Mail dcwither@unm.edu 
such definitions encourage differentiation of micro- and macrodevelopment on little more than quantitative grounds. This, in turn, readily promotes reductionist treatments of time scale relations, whereby macrodevelopmental change is conceptualized as wholly reducible to a concatenation of microdevelopmental activities.

Some prominent dynamic system theorists, in fact, have argued for precisely this kind of conceptualization, arguing that macrodevelopment "has no independent dynamics" and for the "impossibility of drawing distinctions between time scales of change" (Thelen, 1995, pp. 78, 81). Under such conceptual auspices, the emergent patterning and directionality characteristic of macrodevelopmental change are treated as little more than epiphenomenal byproducts of the local shaping dynamics that constitute microdevelopmental change (Spencer \& Perone, 2008; Thelen \& Smith, 1994, 2006). Thelen and Smith (1994), in fact, baldly assert that "developmental time is continuous with and indeed fabricated from real-time experience" (p. 304). Microdevelopment, in other words, determines macrodevelopment, in unidirectional fashion. Such an assertion effectively forestalls any serious consideration of circular relations between the time scales (see Witherington, 2011, 2015, for extended discussion).

Many conceptualizations of micro- and macrodevelopment, however, extend well beyond temporal considerations to specifically highlight qualitative distinctions between the time scales. Lewis (2002), for example, argues that microdevelopment involves "movement to a new or old attractor in real time" whereas macrodevelopment involves "change and consolidation of the system's tendencies, its state space" (p. 186). For Kunnen et al. (2012), macrodevelopment focuses on "broad concepts and on generalized behavioral tendencies, such as autonomy, identity" in contrast to the "real-time day-to-day events and interactions" of microdevelopment (p. 153). For Fischer and Yan (2002), macrodevelopment "adds long-term changes in capacity and framework" (p. 296) to the skill development of microdevelopment. Even in the midst of assigning the same basic process dynamics to both time scales of change, these dynamic systems theorists all critically distinguish micro- from macrodevelopment on qualitative grounds, specifically pointing to differences in what counts as emergent organization for each time scale.

Across each of these qualitatively focused conceptualizations, a broad, unifying theme is evident. To wit, emergent organization at a microdevelopmental time scale constitutes a transformation of what organisms actually do. In contrast, emergent organization at a macrodevelopmental time scale constitutes a transformation of what organisms can do, what they are capable of doing. Put another way, macrodevelopment involves the emergence of new organismic capacities, abilities or powers, in themselves (i.e., changes in an organism's possibilities or potential for acting in the world), whereas microdevelopment involves the emergence of new ways to enact existing capacities, abilities, or powers (i.e., changes in how organisms exercise their powers, not in the powers themselves).

Every action in real time is newly emergent in its own right, "softly assembled" in relation to ever-changing intra- and extraorganismic contextual demands (Thelen \& Smith, 1994). Charting an organism's actions/activities during its ever changing, real-time engagement with the surrounding world/context reveals the transformative patterning of microdevelopment - transformations in the real-time, context-specific dynamics of what an organism is doing or of the manner in which an organism is doing what it is doing. But organismic activity, when considered across time and context, reveals something else. It reveals what organisms are able to do. Charting how an or- 
ganism's actions and activities are organized across time and contexts reveals, in other words, an organism's powers - the bounded range of possibilities open to an organism for engagement with its world. In the midst of persistent microdevelopmental variability and transformation in organismic activity in context, an organism's powers - its potential for acting, or refraining from acting, in certain ways and not others - are dynamically maintained for extended periods of time. These periods reflect the relative stasis of macrodevelopment. During periods of transformation in macrodevelopment, however, an organism's powers themselves transform, reconfiguring the range of possibilities open to that organism for engagement with the world and establishing a new, stable regime of general orientation of the organism to the world.

The notion of power (or ability, capacity, etc.) is itself subject to long-standing conceptual confusion (Hacker, 2007). An organism's powers, as potentials, are not in themselves actualities (Hacker, 2007; Kenny, 1975). They do not, in other words, constitute antecedent forces, processes, or activities, and they do not cause organisms to actually do what they have the power to do. Nonetheless, an organism's powers carry important explanatory weight. The meaning of any given action on the part of an organism necessarily depends on what that organism is currently capable of doing. As organizational characterizations of what organisms can do, an organism's powers entail the range of possibilities available to that organism for various kinds of activities, not the activities themselves. Powers are thus different from and irreducible to their exercise. As such, an understanding of an organism in terms of its abilities is necessarily irreducible to a focus on its activities themselves. The same power, after all, can be exercised in many different ways, and any given action may be indicative of radically different kinds of powers. Furthermore, the fact that an organism happens to once engage in a particular activity does not necessarily indicate that it has the power for such activity, given that any given, isolated activity could simply emerge in real-time context by happenstance and be unrelated to what an organism, in general, can do (Hacker, 2007; Witherington, 2019).

If powers do not cause action, in the sense of serving as antecedent forces, and are not activities in their own right, how do powers relate to their exercise, to activities themselves? The notion of constraint appropriately captures the nature of this relation - not constraint as defined in modulatory or regulatory process terms (i.e., as another kind of antecedent, constructive "force") but constraint as defined in organizational terms (Witherington \& Lickliter, 2016). Constraints do not add anything to an organism's activities; constraints are not constructive forces or dynamics. Instead, they delineate limitations for what kinds of activities are available to the organism (Deacon, 2012; Juarrero, 1999). Powers, as constraints, represent the degrees of freedom within which an organism can operate. Real-time organismic activity is necessarily constrained by what that organism is capable of doing - this is the "topdown" influence of an organism's power on its real-time activities in context. But what that organism is capable of doing is necessarily an emergent outgrowth of that organism's history of activities in context - this is the "bottom-up" influence of an organism's real-time activities on an organism's powers, which are dynamically constructed via an organism's engagement with the world.

Developmentally speaking, real-time activities in context, themselves constrained by existing organismic powers, give rise to new organismic powers, which themselves constrain future real-time activities. Even more abstractly, potentials for activities constrain activities themselves, and activities themselves give rise to poten- 
tials for activities. These interlevel interrelations are emblematic of circular causality, which captures the explanatory importance of both the bottom-up causal dynamics of developmental construction and the top-down constraints of developmental organization (Haken, 1996; Juarrero, 1999; Kelso \& Engström, 2006). Again, it is important to emphasize that the top-down, whole-to-parts influence of an organism's power relative to its activity involves a fundamentally different mode of explanation than that of the bottom-up, parts-to-whole influence of an organism's activity relative to its power. Top-down influence does not operate by generating new activities or by altering existing activities but by topologically constraining the range of opportunities open to an organism for acting (El-Hani \& Pereira, 2000; Moreno, 2008). Powers, via their influence of constraint, thus invoke formal and final levels of explanation, not efficient modes of causality (Emmeche, Koppe, \& Stjernfelt, 2000; Juarrero, 1999; Witherington, 2011, 2015, 2019).

What does all of this mean when framed more specifically in terms of the relation between micro- and macrodevelopment? Microdevelopment is, of course, constitutive of macrodevelopment. Macrodevelopment therefore exists in a whole-toparts relation to microdevelopment, just as microdevelopment exists in a parts-towhole relation to macrodevelopment. Macrodevelopment thus emerges from, but is irreducible to, microdevelopment. Macrodevelopmental organized processes both emerge from microdevelopmental organized processes and constrain, in circular causal fashion, those very microdevelopmental organized processes (Witherington, 2011). Transformations of activities in microdevelopment eventually give rise to transformations of powers in macrodevelopment (via processes of dynamic construction). Emergent organization at the macrolevel of developmental time necessarily constrains emergent organization at the microlevel of real time. From micro- to macrodevelopment, antecedent-consequent dynamics of construction are involved more scientifically orthodox and readily identifiable as "causes" or "processes." From macro- to microdevelopment, however, organizational conditions of constraint are involved - decidedly not definable in scientifically orthodox "causal" or "process" terms. By virtue of the different kinds of "influence" involved in the circular relations between time scales, it is no wonder that the study of relations from macro- to microdevelopment lags far behind that of micro- to macrodevelopment. After all, tackling macrodevelopment's constraining influence on microdevelopment moves us to a whole new level of what it means to "cause."

\section{References}

Deacon, T. W. (2012). Incomplete nature: How mind emerged from matter. New York, NY: Norton; https:// doi.org/10.1558/jsrnc.v9i1.26397

El-Hani, C. N., \& Pereira, A. M. (2000). Higher-level descriptions: Why should we preservethem? In P. B. Andersen, C. Emmeche, N. O. Finnemann, \& P. V. Christiansen (Eds.), Downward causation: Minds, bodies and matter (pp. 118-142). Oxford, UK: AarhusUniversity Press.

Emmeche, C., Koppe, S., \& Stjernfelt, F. (2000). Levels, emergence, and three versions of downward causation. In P. B. Andersen, C. Emmeche, N. O. Finnemann, \& P. V. Christiansen (Eds.), Downward causation: Minds, bodies and matter (pp. 13-34). Oxford: Aarhus University Press.

Fischer, K. W., \& Yan, Z. (2002). Darwin's construction of the theory of evolution: Microdevelopment of explanations of variation and change in species. In N. Granott \& J. Parziale (Eds.), Microdevelopment: Transition processes in development and learning (pp. 294-318). New York, NY: Cambridge University Press. https://doi.org/10.1017/CBO9780511489709.012 
Granott, N., \& Parziale, J. (2002). Microdevelopment: A process-oriented perspective for studying development and learning. In N. Granott \& J. Parziale (Eds.), Microdevelopment: Transition processes in development and learning (pp. 1-28). New York, NY: Cambridge University Press. https://doi. org/10.1017/CBO9780511489709.001

Guevara, M., Cox, R. F. A., van Dijk, M., \& van Geert, P. (2017). Attractor dynamics of dyadic interaction: A recurrence based analysis. Nonlinear Dynamics Psychology and Life Sciences, 21(3), 289-317.

Hacker, P. M. S. (2007). Human nature: The categorical framework. Oxford, UK: Wiley-Blackwell. https:// doi.org/10.1002/9780470692165

Haken, H. (1996). Principles of brain functioning: A synergetic approach to brain activity, behavior and cognition. Berlin: Springer. https://doi.org/10.1007/978-3-642-79570-1

Juarrero, A. (1999). Dynamics in action: Intentional behavior as a complex system. Cambridge, MA: MIT Press. https://doi.org/10.7551/mitpress/2528.001.0001

Kelso, J. A. S., \& Engström, D. A. (2006). The complementary nature. Cambridge, MA: MIT Press.

Kenny, A. (1975). Will, freedom and power. Oxford, UK: Basil Blackwell.

Kunnen, S., Lichtwarck-Aschoff, \& van Geert, P. (2012). The search for relations between micro and macro development. In S. Kunnen (Ed.), A dynamic systems approach to adolescent development (pp. 153-162). New York, NY: Psychology Press. https://doi.org/10.1037/a0016713

Lewis, M. D. (2002). Interacting time scales in personality (and cognitive) development: Intentions, emotions and emergent forms. In N. Granott \& J. Parziale (Eds.), Microdevelopment: Transition processes in development and learning (pp. 183-212). New York, NY: Cambridge University Press. https://doi. org/10.1017/CBO9780511489709.008

Lichtwarck-Aschoff, A., van Geert, P., Bosma, H., \& Kunnen, S. (2008). Time and identity: A framework for research and theory formation. Developmental Review, 28(3), 370-400. https://doi.org/10.1016/j. dr.2008.04.001

Montes, J., van Dijk, M., Puche, R., \& van Geert, P. (2017). Trajectories of scientific reasoning: A microgenetic study on children's inquiry functioning. Journal for Person-Oriented Research, 3(2), 67-85. https://doi.org/10.17505/jpor.2017.07

Moreno, A. (2008). Downward causation requires naturalized constraints: A comment on Vieira \& ElHani. Cybernetics \& Human Knowing, 15(3-4), 135-144.

Spencer, J. P., \& Perone, S. (2008). Defending qualitative change: The view from dynamical systems theory. Child Development, 79(6), 1639-1647. https://doi.org/10.1111/j.1467-8624.2008.01214.x

Thelen, E. (1995). Time-scale dynamics and the development of an embodied cognition. In R. F. Port \& T. van Gelder (Eds.), Mind as motion: Explorations in the dynamics of cognition (pp. 69-100). Cambridge, MA: MIT Press.

Thelen, E., \& Smith, L. B. (1994). A dynamic systems approach to the development of cognition and action. Cambridge, MA: MIT Press.

Thelen, E., \& Smith, L. B. (2006). Dynamic systems theories. In W. Damon \& R. M. Lerner (Series Ed.), \& R. M. Lerner (Vol. Ed.), Theoretical models of human development: Vol. 1. Handbook of child psychology (6th ed., pp. 258-312). Hoboken, NJ: John Wiley \& Sons.

Van Gelder, T., \& Port, R. F. (1995). It's about time: An overview of the dynamical approach to cognition. In R. F. Port \& T. van Gelder (Eds.), Mind as motion: Explorations in the dynamics of cognition (pp. 1-43). Cambridge, MA: MIT Press; https://doi.org/10.2307/417624

Witherington, D. C. (2011). Taking emergence seriously: The centrality of circular causality for dynamic systems approaches to development. Human Development, 54(2), 66-92. https://doi. org/10.1159/000326814

Witherington, D. C. (2015). Dynamic systems in developmental science. In W. F. Overton \& P. C. M. Molenaar (Vol. Eds.), \& R. M. Lerner (Ed.-in-Chief), Handbook of child psychology and developmental science: Vol. 1. Theory and method (7th ed., pp. 63-112). Hoboken, NJ: Wiley. https://doi. org/10.1002/9781118963418.childpsy103

Witherington, D. C. (2019). Embracing agency in all of its explanatory complexity: Essay review of sensorimotor life: An enactive proposal by Ezequiel A. Di Paolo, Thomas Buhrmann, and Xabier E. Barandiaran. Human Development, 62(3), 165-169. https://doi.org/10.1159/000496138

Witherington, D. C., \& Lickliter, R. (2016). Integrating development and evolution in psychological science: Evolutionary developmental psychology, developmental systems, and explanatory pluralism. Human Development, 59(4), 200-234. https://doi.org/10.1159/000450715 